\title{
Linking Gene Dynamics to Intimal Hyperplasia - A Predictive Model of Vein Graft Adaptation
}

\author{
Stefano Casarin ${ }^{1}$, Scott A. Berceli ${ }^{2,3}$, and Marc Garbey ${ }^{1}$ \\ ${ }^{1}$ Houston Methodist Hospital Research Institute \\ 6670 Bertner Ave, Houston, TX \\ scasarin@ houstonmethodist.org; mgarbey2@houstonmethodist.org \\ ${ }^{2}$ M. Randall VAMC \\ 1601 S.W. Archer Road, Gainesville, FL \\ ${ }^{3}$ University of Florida, Department of Surgery \\ Gainesville, FL \\ bercesa@surgery.ufl.edu
}

\section{Extended Abstract}

Myocardial infarct is the leading cause of mortality and morbidity in the western society [1]. Coronary artery occlusion is the main etiology and it is commonly treated by coronary artery bypass using a vein graft. Long-term outcomes are still unsatisfactory [2]. The vein faces the restenosis phenomenon during the post-surgery, which consists in the re-occlusion of the lumen and usually requires secondary intervention within 10 years after the initial surgery [3].

Numerous works have been focusing on the restenosis issue, but significant advances have not been reached yet. The primary cause leading to the vascular adaptation is still not fully understood.

In effect, the root of the re-occlusion must be searched for at genetic level. Accordingly, in the present work we used extensively the vein graft rabbit model developed from Scott Berceli's team to construct a multiscale model that can assess the genetic level of the restenosis and serve as basis for a gene therapy.

Specifically, the goal of our work is to manipulate targeted genes in order to limit the restenosis phenomenon and to accelerate the development of future therapies for vein graft restenosis.

We developed a multiscale model based on two coupled components: (1) a dynamical system that describes the adaptation of a vein bypass graft to mechanical stresses imposed by switching from a venous flow to an arterial one [4], and (2) a gene network system that replicates the expression of targeted genes and details their impact on the main cellular events leading the restenosis.

This innovative hybrid model has been calibrated on experimental data obtained from vein grafts harvested from rabbits. This is a complex process, where a heterogeneous set of data at gene, cellular and anatomy level can be used either for calibration or for further validations.

A gene therapy has been simulated following two principles: (1) by inactivating one-by-one each gene belonging to the network, or (2) by modifying the initial conditions of the gene network itself.

The hybrid model replicated the experimental data with high level of accuracy. Stability and robustness have been systematically tested with a perturbation method. The analysis of the genes' manipulation showed that two clusters of genes are potentially candidate to be knocked down to limit the restenosis. However, the reduction in intimal thickness was rather limited $(21 \%)$.

On the other hand, by perturbing the initial conditions of the gene network, we obtained an overall reduction of the intimal thickness of $69 \%$.

The "in silico" model developed is accurate, fast to run, easy to use and predictive.

We obtained a more significant impact on the restenosis reduction by modifying the initial conditions of the gene network than with the inactivation of the genes. Consequently, this will be the basis for our future work. A first step will be to look for a minimal set of genes manipulation leading to significant improvements and that can also be tested with existing drugs. 


\section{References}

[1] Roger et al. American Heart Association Statistics Committee and Stroke Statistics Subcommittee, "Heart disease and stroke statistics - 2014 update: a report from the American Heart Association," in Circulation, vol. 129, no. 3, pp. e28-e292, 2014.

[2] B. W. Lytie, F. D. Loop et al, "Long-term (5 to 12 years) serial studies of internal mammary artery and saphenous vein coronary bypass grafts," in The Journal of Thoracic and Cardiovascular Surgery, vol. 89, no. 2, pp. 248-258, 1985.

[3] G. M. Fitzgibbon et al, "Coronary Bypass Graft Fate and Patient Outcome: Angiographic Follow-Up of 5,065 Grafts Related to Survival and Reoperation in 1,388 Patients During 25 Years," in JACC, vol. 28, no. 3, pp. 616-26, 1996.

[4] M. Garbey, S. A. Berceli, "A dynamical system that describes vein graft adaptation and failure," in Journal of Theoretical Biology, vol. 336, pp. 209-220, 2013. 